to buy animals from the centre, which charges $£ 15$ for a cat. In the long run, however, Mr Bleby maintains that carefully bred, often vaccinated and genetically defined animals obtained from the centre are more economical as fewer need to be used.

About 90 per cent of all animals used in experiments in Britain come from commercial breeders who are under the direct control of the Medical Research Council. This accredited breeders scheme was started by the Laboratory Animals Centre in 1950 to boost large-scale production of the animals, and is voluntary. But the demand for specialized strains of animals has become so great that the breeders alone cannot cope and the centre now maintains a number of strains from which breeding nuclei are supplied. Together with the specific pathogen free (SPF) and germ-free animals, these breeding nuclei have become a major feature of the centre.

SPF animals are, as the name suggests, without disease, but they still have a normal gut flora. Germ. free animals, on the other hand, are completely without bacteria and the technical difficulties in rearing these animals are considerable. For this reason, the rearing of small germ-free animals at Carshalton is still at the pilot stage under the direction of Dr D. K. Blackmore. These animals will be used to restock the SPF unit should any mishap occur there, such as infection of the animals. They can also be used, however, in specific studies such as determining the synergistic effect of certain bacteria or, as Dr H. B. Stoner at the centre suggested, to find out why some food additives become toxic in the human body; this could either be a result of the action of the gut flora, or part of the normal human metabolism.

Germ-free swine and cattle are also being reared at the Royal Veterinary College, London, with considerable success. Here they are being used by Dr P. C. Trexler and his colleagues to study respiratory diseases; for the production of monospecific antisera against viruses; and for investigating the role of the normal bacteria in the economy of the animal. Even more striking is the news that a human child was born in December under germ-free conditions. The reason for this strange delivery was given by Mrs M. Tuffrey at the Institute of Child Health and is that the child had a one in four chance of being born with a specific defect of the immunological mechanism; the mother had already lost one child as a result of this defect. The child was therefore delivered prematurely by caesarean section in a specially designed isolator at University College Hospital, and was then transported in an isolator to the Institute of Child Health where she was kept in a maintenance isolator for seven days during which time she was fed on sterile canned milk. As it turned out, the results of a number of tests carried out during this time showed that the child was in fact normal, but Mrs Tuffrey said that it could have been kept in isolation for up to one month had the need arisen. She added that as babies usually die as a result of this deficiency at four months, there would have been time for the clinicians to diagnose and try to treat the disease, perhaps by grafting immunocompetent tissue such as the thymus. Mrs Tuffrey suggested that the treatment of patients who are unduly susceptible to infection in a protective environment such as a germ-free isolator would be useful in a number of diseases such as leukaemia, burns and, of course, in helping those transplant patients receiving immunosuppressive treatment. Whether or not gnotobiotics has advanced sufficiently to justify the delivery of a human child under germ-free conditions seems, however, debatable.

\section{Hot Soak for Seeds}

ONE of the best ways to spread plant diseases is through the sale and shipment of seed. In some cases, such as celery leaf rust, only one infected plant in 10,000 is needed to cause an epidemic in the crop. Particularly critical are fungal diseases lodged within the seed where seed dressings cannot reach them. The problem in dealing with these diseases has been to kill the fungus but not the seed.

This type of disease can now be completely eliminated by a process developed at the National Vegetable Research Station (near Warwick) which was on view at last week's Chelsea Flower Show. The treatment is first to soak seed for twenty-four hours in a solution containing 0.2 per cent of the fungicide 'Thiram' at $30^{\circ} \mathrm{C}$. The seed is then dried by driving air through it for several hours. So far this treatment has been found to give complete control in eleven commercially important plant species with infections involving eighteen different seed-borne diseases. The plants, with the number of specific diseases which can be controlled given in parentheses, are: pea (2), celery (1), carrot (2), brassicas (2), beet (3), trefoil (1), flax (1), oats (1), wheat (2), barley (2), lobelia (1); tick-beans have shown 70-80 per cent control. For the many flower seeds which are sensitive to the treatment the concentration of the soak is cut by half.

For the first time this year the principal celery seed company in the United Kingdom is selling 'Thiram' soaked seed. Dr Keyworth, the head of the plant pathology department at the National Vegetable Research Station, points out: "We've now got a method where we can give 100 per cent guarantee that seeds are free from fungal disease and this is the very first time that anyone anywhere can say this"'. This should have sales appeal abroad. The treatment also substantially increases germination rates and this makes it popular with growers. The economic advantage of seedsoaking over controlling a disease in the field is great. A few pence for seed treatment as against $£ 100$ to spray for celery blight in a ten acre field is a comparison which has been quoted.

\section{Disease as a Social Problem}

The Arthritis and Rheumatism Council for Research and the British Rheumatism and Arthritis Association have together compiled a report on the social consequences of arthritis and rheumatism. The most interesting parts of this report are drawn from a more analytical statistical study on arthritis in Britain by the World Health Organization.

It is estimated that some 30 million working days are lost in a year as a result of arthritis, at a cost to the country of $£ 130$ million. Miners, because of the often cramped conditions of their work, have the highest number of lost days-134 days lost/100 men/year. Then come electrical linesmen, lorry driver mates and other jobs connected with lifting heavy loads. At any 